\title{
African Refugee Youths' Stories of Surviving Trauma and Transition in U.S. Public Schools
}

\author{
Badiah Haffejee, MSW
}

Graduate School of Social Work University of Denver

\section{Abstract}

The educational landscape for the United States has continued to shift with the arrival of African Muslim youth with refugee status. This phenomenological study examines the lived experiences of college-aged refugees (ages 18-22) attending various public (community and 4-year) colleges in the western United States. The participants' $(N=12)$ narratives address the carryover effects of trauma including the challenges of racism, discrimination, and Islamophobia. This discussion further explores the ways in which African refugee youth navigate and survive these sometimes discouraging challenges within their school setting. The findings suggested that strong parental bonds, religiosity, ethnic and cultural solidarity, as well as youths' determination and motivation to attain their academic goals counterbalanced hostile experiences from their U.S.-born peers. This article concludes by (a) proposing that educators look beyond curriculum goals and the depersonalized structures, and (b) reasserting the important role of social workers in academic institutions providing culturally responsive mental health services to African Muslim students from refugee backgrounds.

Keywords: African refugees, youth, trauma, racism, education, resiliency

"An immigrant leaves his homeland to find greener grass. A refugee leaves his homeland because the grass is burning under his feet."

-Law \& Eckes (2000)

An influx of youth with refugee status from war-torn regions such as Ethiopia, Somalia, and Sudan has changed the landscape of the American classroom (Tadesse, Hoot, \& Watson-Thompson, 2009). Scant literature addresses 
the lived experiences of predominately African youth with refugee status in learning spaces (Hek, 2005; Matthews, 2008; Shakya et al., 2010). Limited existing literature in host nations, such as the U.S., focuses the research on youths' trauma experiences (e.g., torture, war, and violence). Consequently the youth become defined by their trauma experience (Fazel, Reed, Panter-Brick, \& Stein, 2012) rather than their trauma being accounted for in their lived experience. The current study aims to add to the small but growing body of literature, and examines the way African students who identify as Muslim survive engagement with their American peers in an educational space.

\section{Background Literature}

The road to the U.S. is difficult for refugee youth. Refugee youth often leave familiar people, places and surroundings, survive perilous journeys and traumatic events, and reside in refugee camps for several years, waiting to be resettled in a country foreign to them (Deacon \& Sullivan, 2009; Ovitt, Larrison, \& Nackerud, 2003). Refugee camps vary in the support and resources provided. Some refugee camps may be well-established and have organized housing, food distribution, and education opportunities, while others may lack even the basics of clean water and sanitation (Kanu, 2008; UNHCR, 2012).

Due to years, or sometimes decades, of instability in their natal countries, refugee adolescents often bear deep emotional scars (Fong, 2007; McBrien, 2005). In addition, many children and adolescents do not have an opportunity to attend school and learn basic skills in their native tongue (Onsando \& Billett, 2009). Despite these challenges, these young newcomers arrive to the U.S. with high aspirations for academic success (Shakya et al., 2010) and a future that provides a sense of safety and security (Segal \& Mayadas, 2005).

\section{The New Face of American Classrooms}

Over the last twenty years, immigrants and refugees account for almost all of the national increase in American public school enrollment (Camarota, 2012). In 2007, there were approximately 10.8 million school-aged children from refugee and immigrant families in the U.S., and it is estimated that children from refugee and immigrant families may represent 30\% of U.S. students in 2015 (Annie E. Casey Foundation, 2007).

Educational institutions are a stabilizing aspect in the lives of resettled youth (Matthews, 2008). They offer a safe space for social and emotional development, discovery and exploration, and learning opportunities (Fazel \& Stein, 2002). They also deliver literacy - the recipe for educational success, social participation, career options, and life choices (Taylor \& Sidhu, 2012); yet, many 
students with refugee status, like immigrant youth, fall behind academically. Although they increase in English proficiency over their years in U.S. education, they struggle with other markers of academic success (Suárez -Orozco, Pimentel, \& Martin, 2009). Although foreign-born youth (ages 16-24) constitute $10 \%$ of the total population in this age category, they make up $21 \%$ of the dropout population; children of foreign-born parents represent $25 \%$ of the overall population, but comprise $35 \%$ of dropouts (Child Trends, 2013).

The U.S. school systems are often ill-prepared to meet the needs of African refugee students. Students from refugee backgrounds often face experiences of exclusion and marginalization from culturally uneducated teachers and non-refugee peers (Kanu, 2008; MacNevin, 2012). Further, many U.S. public schools have limited experience with, and capacity for, recognizing and meeting the diverse needs of newcomers. Consequently, a large number of students with refugee status fall through the cracks (MacNevin, 2012; McBrien, 2005).

The common solution to African youths' educational gaps and language barriers is to support academic success by granting refugee status and encouraging rapid English acquisition; but few additional educational resources are typically offered (McBrien, 2005; Rossiter \& Rossiter, 2009). Language acquisition alone is often not sufficient, as African refugee youths' experiences of past trauma and struggles with integration into the U.S. bring complex challenges beyond the prioritization of learning English (De Anstiss \& Ziaian, 2010; Kugler, 2009).

\section{Pre-Migration Trauma Experiences}

In the U.S. context, trauma and its impact on academic achievement for African youth with refugee status is still relatively unexplored (Ellis, MacDonald, Lincoln, \& Cabral, 2008). Nevertheless, a wide body of literature indicates that premigration experiences such as witnessing war atrocities (Abu-Ras \& Abu-Bader, 2009), separation from family, uncertainty about the future, harsh living conditions, and poor nutrition adversely impact refugee youth (Pacione, Measham, \& Rousseau, 2013). Forced displacement from the home environment exacerbates "traumatic experiences by disrupting a child's sense of attachment to their home, familiarity with their surroundings and a sense of self that develops from spending one's life in a specific place" (Pacione et al., 2013, p.2).

Furthermore, unaccompanied minors are at greater risk of emotional and behavioral problems due to their exposure to traumatic experiences (Pacione et al., 2013). Children from families who have endured trauma are particularly susceptible to delinquent (i.e., substance use and aggression) behavior, psychiatric illness (Daud, af Klinteberg, \& Rydelius, 2008) and low academic achievement (Kugler, 2009). Ellis and colleagues' (2008) research with Somali adolescents in the U.S. provides evidence that cumulative trauma is related 
to symptoms of depression and posttraumatic stress disorder (PTSD). Those youth who perceived heightened discrimination and acculturative stressors (Ellis et al., 2008) post-migration were more likely to experience PTSD symptoms (Abu-Ras \& Abu-Bader, 2009). Such mental health symptoms can magnify the refugee youth's sense of separation, loss, displacement, and marginalization as they attempt to engage in the school environment (Abu-Ras \& Abu-Bader, 2009; Shakya et al., 2010).

\section{Racism and Discrimination}

As noted, schools are complicated environments for youth with refugee status. On the one hand they can provide a sense of belonging, and on the other hand, youth who are Muslim or perceived to be Muslim, often experience negative attitudes, bullying, and physical assault (Aroian, 2012) by peers within their supposed-to-be-safe learning environments (Zine, 2001).

African Muslim youth represent several marginalized identities, making them targets for discrimination. As Muslim youth in post-9/11 America, they are religious minorities that experience considerable racial and ethnic harassment (i.e., hate crimes, name calling, and physical assaults; Abu-Ras \& AbuBader, 2009; Aroian, 2012; Casimiro et al., 2007; Khanlou, Koh, \& Mill, 2008). Muslim students often do not report experiences of harassment (Aroian, 2012) for fear of reprisal. As a result, they feel isolated (Kirova, 2001) from their nonMuslim peers and/or "suffer quietly" (Shakya et al., 2010, p. 2).

African refugee youth also face discrimination due to perceived ethnic and racial differences. School administrators and teachers both discriminate against refugee students because of their ethnic/racialized identity and perceived social location (Shakya et al., 2010). Not only do these students face discrimination from those in positions of power, their American peers often also view them as inferior and unintelligent (Shakya et al., 2010). In fact, Ellis and colleagues (2008) contend that discrimination and fewer years living in the U.S. are associated with depression, especially for Somali youth in the U.S.

African students with refugee status live in a marginalized space where they look black and are treated by the dominant society as African American and yet they are not in-group members of this community (Tadesse et al., 2009). In this way they encounter racism, discrimination, and hostility from both the African American community and society at large (Hek, 2005; Matthews, 2008). This runs counter to the common assumption that, because African refugees are phenotypically black, they would be welcomed by their African American peers. Their minority status and othering (a way of reminding a group of their outsider status or perceiving them as fundamentally different due to language, history, culture, and traditions) separates them from historically underrepre- 
sented groups in U.S. society. They endure compounding effects of overt and subtle degrees of discrimination from those who also are racialized minorities and experience discrimination (Darboe, 2003; Hauck et al., 2012; Laird, AbuRas, \& Senzai, 2013; Tindongan, 2011).

Scholars assert that discrimination is a significant barrier to integration for refugee students (Ellis et al., 2008; Shakya et al., 2010). In fact, Ellis and colleagues (2008) study of Somali refugee youth suggests that perceived discrimination is highly correlated with mental health outcomes even after historical factors and other resettlement stressors have been taken into account. Discrimination has a lasting impact on youths' motivation, self-perception, and self-esteem (Kirova, 2001) and may lead to depression (Ellis et al., 2008). Despite refugee youths high educational aspirations, fear of discrimination and violence (e.g., bullying) leads youth to self-select out of participation in peer social interactions, leading to isolation, and negatively affecting academic attainment (McBrien, 2005; Suárez-Orozco \& Suárez-Orozco, 2001).

Research indicates that during journeys to and upon arrival into host societies, many young refugee voices remain silent about their experiences (including trauma), feelings, and hopes (Matthews, 2008; Anjum, Nordqvist, \& Timpka, 2012). This silence prompted the current study, its approach, and methodology. Specifically, this study employed qualitative methods to amplify the voices of African refugee students in regards to their experiences attempting to integrate into the U.S. educational system. Understanding these voices will inform the development of services to aid these vulnerable yet resilient youth in achieving integration and academic success in their new homes.

\section{Methodology}

\section{Participants}

This research was undertaken at the end of 2012 as part of a larger phenomenological study investigating factors affecting African refugee students in the U.S. public school system. Data analyzed for this paper is from a sample $(\mathrm{N}=12)$ of African Muslim refugee students (ages 18-22) attending various public (community and 4-year) colleges in the western United States. Most had little-to-no formal education in their countries of origin, and arrived to the United States as youth (ages 5-15 years old). All participants are proficient in three to five languages/dialects, one of which is English. At the time of the interview, participants were living in public housing, and in predominantly low-income and underserved neighborhoods in a large metropolitan city. 


\section{Procedures and Measures for Data Collection}

A combination of purposive and snowball sampling was used to recruit participants. The research was promoted at four afterschool programs that provide academic services to children ages 3 to 18 from low-income families and serve large populations of African refugee families. One, in-depth, 60-90 minute face-to-face interview was conducted at a location most convenient to each participant in the study. At the beginning of the interview, participants were provided with the informed consent form that explained the purpose of the study, the type of questions they would be asked during the interview and that the interview would be recorded. Data was collected with institutional review board (IRB) approval.

An interview guide with the relevant open-ended questions structured the face-to-face interviews. The interview guide included questions that asked the participants to, among other things, describe (1) the reasons their family came to the United States, (2) their experiences as a refugee integrating in a predominantly English-only school, (3) the challenges of integrating in school, and (4) what it means to be going to school in the U.S. All interviews were audiorecorded with participant permission and transcribed verbatim.

\section{Data Analysis}

Transcripts were analyzed using the data management system Atlas.ti (Muhr, 2004). Data were analyzed through several iterations, following the constant comparative method (Boeije, 2002). The researcher completed an initial analysis during which the transcripts were examined for in-vivo codes: key phrases directly quoted from the respondents' answers to begin to organize and categorize the data. In-Vivo Coding was used to keep the data rooted in the participants' own language and to honor their stories (Saldaña, 2009).

Pattern coding as a second cycle coding was used to analyze the participants' responses to the semi-structured guide (Saldaña, 2009). This technique was useful as it provided a structured and beneficial way of pulling together recurring and what appeared to be major themes from the data to begin to search for meaning, and "rules, causes, and explanations" (Saldaña, 2009, p.152) within the data. Next, the researcher created preliminary categories based on related quotes. The faculty supervisor and two doctoral students reviewed the process and categories and this allowed for cross network analysis in order to merge overlapping themes and create new ones (Saldaña, 2009). Qualitative analysis involved member checking to establish quality of interpretation during and after data collection (Creswell, 2007). Analytic memos were also utilized. 


\section{Results}

\section{Sample Characteristics}

Muslim youth (7 male and 5 female) identified as predominantly Somali-Bantu but also included Somali-Somali, Somali-Yemeni, Ethiopian, and Liberian. The sample was linguistically diverse, with languages/dialects ranging from afMaay Maay, Swahili, Somali, Amharic, Arabic, French, and Kreyol. The entire sample had experienced one or more traumatic events (e.g., war, witnessed the death of loved ones and/or relatives, rape, and sexual violence). Participants also lived in refugee camps (sometimes moving to several camps) for a minimum period of 5 years and maximum of 11 years. One participant arrived in the U.S. as an unaccompanied minor. At the time of the interview, most youth reported that they arrived in the U.S. between the ages of 11-16 and had lived in the U.S. an average of 6.2 years.

\section{African Youths' Stories}

Three major themes emerged from the analysis: 1) carryover effects of trauma; 2) racism, discrimination and Islamophobia; and 3) surviving two worlds. The first theme, carryover effects of trauma describes youths' personal experiences that include their continuing hardships even as they are trying to integrate into the U.S. educational system. The other two themes: 1) racism, discrimination and Islamophobia, and 2) surviving discrimination and othering illuminate the experiences of African Muslim students in a school setting. In particular, these themes provide an understanding of how these youth interact with and survive engagement with their American peers.

\section{Carryover Effects of Trauma}

The participants' narratives were replete with multiple accounts of traumatic experiences including how such experiences affect meaningful integration in an educational setting. The experiences described were very diverse; however, they shared similar patterns: the fleeing from their homes and towns because of civil war in their natal countries; surviving perilous journeys in search of safety; the loss of family member(s); and witnessing the murder of a loved one and violence within the refugee camps.

One participant's story is a poignant example of the unimaginable transition from home village to overcrowded camp life. Born and raised in a small, stable village in Somalia, he "... and his mother watched [his] dad being killed." Immediately thereafter, his family journeyed on foot for several days to the Dadaab refugee camp in Kenya. 
It was so difficult ... so many people from all over Somalia - it was hundreds, maybe even thousands living in the camp - they did not like us because we are Somali-Bantu - we speak af-Maay Maay, so they see us as not the same as other Somalis.

A similar experience was shared by another participant, noting that ". . . some of the Somali-Somali people are good but some of them hated the Somali-Bantu - they hated us." Consequently, in-camp violence against the Somali-Bantu became an ever-present phenomenon, as remembered by one participant: "That's where I got hurt and now I have [partial] hearing only. ..." Another example of in-camp tensions is exemplified in the following comment made by a female Somali-Bantu participant: She said,

... in Africa we don't sleep at night because it's so dangerous. During the day we sleep ... you must learn to survive ... sometimes we go to school [in the camp] hungry.... In a refugee camp you are always around people who are struggling like I was and it put everyone into survival mode.

Another male participant said that his family (which included his mother and younger siblings) also hastily fled their home and lived in the Kakuma refugee camp in Kenya for 11 years. In his words, "Somalia [is] crazy! Several men came into [their] home" and fatally "shot his two older cousins" and severely injured his aunt while he was in the home. "It [the experience] was just crazy . . . I can't believe that people can do such things!" While this respondent described this experience as life altering, he aptly pointed out that he is "still alive ..." For him, dealing with the "bad memories" on a regular basis was "better' or 'easier" than the "pain" that his aunt had to endure. Despite this, he continued to describe the emotional scars that still linger saying, "Most nights I have dreams - like there's too much things going on in my head ... I still see things that I don't want to see in my sleep." A female participant echoed a similar experience saying,

... coming here [to America] it was much more stable. I was happier! All the things that a child needs: a stable home, school, and everything. I was just happy! So the first couple of years - is usually nice. Later on, it did get difficult again! Stuff that I buried started resurfacing.

The frequent recollections of traumatic experiences such as the recurrent memories, images, flashbacks and nightmares of trauma are distressing. Youth expressed that they still "jump" when "[they] hear a loud noise." Further noting that, due to increased sensitivity to change (e.g., new peers, educators and environment) they are often "careful" and "watchful" of others both inside and outside the classroom. For these youth, it is also "difficult to be with so many 
new people." Consequently, youth mentioned feeling very "isolated" and often "not part" of their learning community.

Refugee students willingly talked about their emotional scars. However, it was clear that concepts such as trauma and mental health (i.e., depression, PTSD, and anxiety) were foreign concepts for most of these youth. Some youth described it as their "minds are just full of raw images ... and sometimes [they] can't sleep at night" resulting in them feeling "tired" and "falling asleep" during lectures. Others echoed similar sentiments reporting that they ". . witnessed bad things and these are things [they] worry and [think] about all the time." Memories from youths' past trauma experiences affect how youth engage and respond in the classroom. For example, one male respondent reflected that, "It feels like my brain doesn't work," and that mostly, "it is hard to concentrate."

Youth not only discussed some of their struggles in the classroom, they also highlighted the lack of understanding by educators. For example, youth utilized culturally specific language and described how it sometimes "feels like [they have] too much air in [their] brain ..." which can be "hard to deal with" while trying to attain academic success. "Nobody understands. It's important to learn English and get an education, but our teachers really don't know what we go through every day. [Teachers including school social workers] have never asked us how our [traumatic experiences] affect us, it's hard you know." In spite of this, youth said that they have to "study hard" so they can be "successful in school."

While respondents felt comfortable sharing their trauma experiences with the researcher, it was evident in some of the youth's stories that trauma experiences were also not talked about within their families - among adults or with children. For example, several participants noted their "parent(s) don't ever talk about the civil war" even about the parent who "was killed in Somalia." One male participant reported that, within his culture, talking about these experiences whether in the present or past is viewed as inflicting more stress onto the children and/or family. Still, he worries about his mom since he now has a better understanding of their traumatic experiences in Somalia. A female participant revealed that not only is,

... [Trauma] not talked about in [her] culture, whatever happened to you happened. You only can complain to Allah [God], you can't complain to anyone else, you keep it to yourself and things like that. . . you know, you don't show emotions, you don't show what's happened to your mental health, it's like mental illness is a stigma, and it's not talked about.

Another youth discussed multiple traumatic events that occurred before the age of 15: First, the "... death of [her] youngest brother due to insufficient medical care in the refugee camp." Second, witnessing "[her] mother being 
raped while she and [her] dad stood by helpless." Thereafter, “. . . life in the refugee camp in Somalia was becoming very, very bad" and the family traversed for several days to the refugee camp in Yemen. Not long after that, her dad abandoned the family because he could not cope with both the death of a child, the sexual violence perpetrated against his wife, and his inability to protect them. This participant not only shared her pre-migration traumatic experiences, but also the impact of her own mother's trauma on her even as she is trying to cope as a Muslim college student in post-9/11 America. For example, she said,

My mom is still very scared to walk outside [in the U.S.] by herself. She thinks she will get raped again. Actually, she refuses to even take a bus on her own unless I am with her. I am always with her and that seems to make her more comfortable.

Similar to other youth in this study, this participant articulated that, as a family, they never discuss their "bad" experiences. "It will make my mother sad ... and she wants her children to be happy and learn . . . to get a good education." Youth described that educational attainment is also extremely important but "... . it's hard to sometimes cope with everything [family and school obligations] . . . there's no one to talk to. No one understands." Students' sentiments were that they have to process their past experiences of trauma alone, especially the multiple ways that their traumatic experiences affect their ability to learn. Further pointing out that "it's the first time since moving to America" that youth have had to tell their story.

\section{Racism, Discrimination, and Islamophobia}

One of the most salient experiences of African Muslim students within the school relate to racism, discrimination, and Islamophobia. It was evident early on that all respondents' interviewed did not identify by a particular race in their countries of origin nor had they heard the term before coming to America. Within the U.S. context, however, school and the dominant society characterized these youth as Black/African American. Overwhelmingly, youth expressed that, if in the U.S. context they needed to be characterized, they preferred African or by their respective ethnicity (i.e., Ethiopian, Somali, etc.).

Given the history of the word black in the U.S., and the negative connotation associated with it, it is not surprising students remarked that they were "offended" by the imposition of the characterization of Black/African American by the school. For them, their Africanness is paramount: "We are proud to be African. It's not like we are treated like we are African American by other students. They see us as different ... as backward Africans." Another statement captures one such experience: 
... I would see people [African American students] that looked like me but they didn't sound like me and they were of a different culture. They did not even consider us the same so they treated me in a different way you know. They considered us to be filthy sitting in the bus - kids would tease me and say that I stink.

Participants emphasized the ongoing incidents of racism and discrimination related to being mistaken for African Americans by students of all races. Notably, black students engaged in the most troubling interpersonal conflict:

... African American students ... they really laughed at me a lot, and at times they would make some racist comments to me. At lunch, I would sit by myself and think - Why am I here? What am I doing here? But it was part of my education so I got used to it, you know.

Especially poignant is one student's account of feeling othered in school. He said, "You know when you're African and you look different, some of the kids teased me. Saying some bad words about me ..." These sentiments were echoed by another student saying, ". . . in middle school . . . students would tease me and then I would get into trouble because they are the ones that start it. I don't like trouble but the other kids they say not so good things."

African refugee students also described their experiences with White peers. A student related how his English was less developed when he arrived in the U.S. Nonetheless, he was placed into the $6^{\text {th }}$ grade based on his age and not his English proficiency. Moreover, the school did not provide additional support to English language learners. Consequently, he struggled with classroom content as well as the constant harassment from his White peers. The following statement exemplifies his experience:

... In [a] community and school that were predominantly white ... only white students everywhere you looked. I was like 'wow!' They [white students] did not even speak to me. The teachers did their best to help me but the students would bully me and say hurtful things. It was hard for me to make friends - I didn't have any friends, I felt so lost. I felt like I was a stranger, like I did not belong. It would maybe be better if I spoke some English you know...

Students not only spoke of the interpersonal discrimination experienced by non-refugee students, almost on a daily basis, they also mentioned that the school administration tended not to listen to their explanations about the genus of peer conflict and they would end up being identified for suspension: "Here in America they suspend you for everything." A similar remark was made by 
a female student who was called into the principal's office because "one girl insulted [her] and the other girl jumped [her]." She did not understand why she ended up in the principal's office even though she felt that she was not at fault. She went onto say that:

I am not too good with speaking English but they didn't explain anything or call my parents. They gave me this paperwork and took me away but I don't know how to read it. I really did not even understand why or what the paper was about. I went to the court and I was suspended from school for two weeks. At first, I was so scared I thought it was a jail.

One of the respondents who also faced suspension said “. . . [He didn't] think that it was fair. On the other hand, I guess it's fair because I wasn't born in the U.S. - why should they [school administration] want to invest in me."

Female participants reported higher incidents of Islamophobia (by both students and culturally uneducated teachers) coupled with offensive comments and gender misconceptions about wearing hijab (the headscarf). A female student shared these sentiments:

[Westerners] ... think that [Muslim women] are oppressed by our husbands, men, religion or society when we wear the hijab. We're not! It's our choice; nobody's forcing us to wear it . . . students were really nasty . . . we say there is no racism - but there is racism - all around us, everywhere, I believe. I experienced it.

Another respondent explained that her classmates would wait until she was in the girls' restrooms to confront her about her traditional clothing. She said: "They would ask why I was wearing the hijab" and whether ". . . I was bald." Her peers were verbally abusive and treated "[her] differently." It was "hard" because "I could not [respond]" due to a lack of English. She eventually "became very quiet and [withdrawn]." Some participants reported that "American culture has definitely influenced their friends. What they see on TV, hear on the news ..." impacts their perspectives. Actually, “. . it's never about learning about our [Muslim] culture or Islam. It's always about learning the American way - the Protestant way."

One respondent volunteered an incident with her teacher when she requested to take time off for Eid [Islamic holiday]. First, she was subjected to countless questions. After respectfully answering them, her teacher thought she was "lying" and asked "... why [she] needed to take two days off - missing two days was just not acceptable." She responded, “. . . we take off time for Christmas ..." Although the participant emphasized the significance of the religious holiday and being with her family, out of fear, she decided against taking 
time off from school. Further pointing out that it is customary in her culture to respect persons in position of authority. However, this interaction reinforced that "[her] culture or religion is not valued."

\section{Surviving Discrimination and Othering in School}

There were some gender differences in the narratives of how respondents' navigate experiences of discrimination and/or othering. Girls explained that they employed various strategies within two often-conflicting cultural paradigms: the dominant culture and their culture (i.e., ethnic or Muslim). Boys reported that they mostly "ignored" the perpetrators out of fear of suspension, but at some point a few chose to "blend" in with mainstream students, particularly with students of color.

A female participant discussed how "from an early age, [she] learned how to conform ... how to be American." According to her, the "whole schooling process is to socialize [one] into learning the etiquette and the [dominant] culture ... what's valued [in the U.S.]," which was definitely "how not to be African." For example, early on she learned unaccented English after she realized that minority groups "who have an accent are treated differently, and viewed as ignorant and inferior." Later on, she learned how to "think and act like them [Western culture] ..." aptly noting that "acting is not becoming" an American. In contrast, at home, she was acutely aware that she is:

... still Somali and Muslim ... I am still expected to adhere to certain cultural values (i.e., not smoke or drink alcohol, no dating, 9 o'clock curfew). Sometimes, I had to kind of like be a different person - role play here [in school] and take on a different role in front of my parents. It was very conflicting - those two different realities. They always seem to clash.

Another respondent made an effort to educate her non-Muslim peers and also resist cultural conformity by continuing to "wear hijab." Despite the insults and offensive comments, she explained, "I am proud to be Muslim. It's [therefore] important to wear [hijab] so that I can teach people when they ask questions. So they will not be mistaken or [stereotype us] when [we] walk outside." Others revealed that the "[American] culture is not something that benefits [them] - this culture refuses to see us as anything other than a refugee - someone that deserves only pity." For these youth, “... America's diversity ..." includes: "White, Black/African American, Native American, Pacific Islander, Asian, and Latino/a. Africans are excluded" or at least not "included" in the defined identity categories even "after [they have become] naturalized citizens." Thus, they are steadfast about "maintaining their [respective] ethnic/cultural traditions and values ... its better ... it helps us when we are in school." 
One male participant who described being bullied and taunted said:

It was not until I started to blend in with mainstream culture, whether I liked it or not that things started changing . . . I started to earn money . . . dress like American teenagers. When I started to look like an African American more students started accepting me.

Other male students code-switched or reflexively changed the way they expressed themselves - adopting contemporary slang phrases like "That's so dope!" when they were among their peers of color, particularly, African Americans.

Both groups spoke fondly about how influential their parent(s)/guardians are, despite having lower English skills and little-to-no formal education. They emphasized positive parenting, showing "concern," receiving daily "encouragement and support" to be academically "better," "to go to school" and not to waste this educational opportunity afforded them. They also discussed how coming from adversity helps them navigate the challenges of school. It gives them the "strength, courage, and determination" to be "successful college graduates so that someday they can return to their roots and make a difference. Home is still in Somalia, Kenya, or Ethiopia."

\section{Discussion}

This study sought to amplify African refugee students' lived experiences that are often silenced. Youth spoke powerfully and poignantly about the ways in which they experienced pre-migration trauma; racism, discrimination and Islamophobia, and how they navigate these sometimes disheartening experiences within educational institutions. This is important to our understanding of how pre-flight trauma, including other social sites of difference, such as race, ethnicity, culture/religion, and language variously affect the way schooling is experienced for African Muslim youth.

The effects of war or armed conflict and trauma on the subsequent resettlement of refugee students are relatively unexplored. Based on the data available on trauma and related mental health symptoms of refugees resettling in the U.S., we know that symptoms such as depression and PTSD affect meaningful integration for a significant portion of newly arrived refugees. While not accounted for in schools, trauma experiences and related mental health symptoms were found to be a significant part of African refugee youths' lived reality; it is especially pronounced in how youth articulate enduring symptoms of trauma and their impact on educational integration. Furthermore, most refugee students may lack the prerequisite knowledge to seek help for their mental 
distress; this can largely be attributed to the failure on the part of mental health professionals in schools to effectively engage African refugee youth.

This study results further attests to the need for culturally relevant interventions in educational institutions that are: responsive to refugee explanatory frameworks of mental health; offered to youth in a format that they are amenable to (De Anstiss \& Ziaian, 2010); in a non-stigmatizing and youth-friendly community setting (Miller \& Rasco, 2004) and staffed by culturally astute (Andary, Stolk, \& Klimidis, 2003) school social workers. Consistent with emerging studies (De Anstiss \& Ziaian, 2010; Hodes, 2002), results also suggest that interventions might be more acceptable if they respond to practical and social concerns in addition to the mental health needs of refugee youth.

While mental health interventions for refugee youth are still evolving; some Western therapeutic models have been shown to be effective in treating mental health disorders among refugees (Pacione et al., 2013), and these should be considered. For example, Narrative Therapy (NET; Ruf et al., 2010) acknowledges the narrative tradition common to most refugee cultures and Cognitive Behavioral Therapy (CBT; Hinton et al., 2005) or Trauma-Focused Cognitive-Behavioral Therapy (TF-CBT) was found to be effective (both individual and group interventions) in the treatment of anxiety, PTSD, depression, peer-problems and functional disturbances (Pacione et al., 2013; Slobodin \& de Jong, 2015; Tyrer \& Fazel, 2014). As brought forward in this study, parents or caretakers exposed to similar traumatic encounters may suffer similar psychological distress that affects the entire family's emotional and physical wellbeing. Thus, comprehensive or multimodal interventions that aim to concurrently address issues of psychological functioning, physical health and ongoing psychological difficulties with refugee students and their families (Tyrer \& Fazel, 2014) should also be considered, thereby strengthening intrafamilial coping resources.To this end, within schools, school social workers, staff/teachers, lay therapists or cultural brokers could be trained to promote mental wellbeing by creating a caring and supporting environment and through implementation of preventative and efficacious psychological functioning (Tyrer \& Fazel, 2014).

The findings that African Muslim refugee youth are targets of racism, discrimination, and Islamophobia is not surprising in an anti-Muslim and racialized U.S. society (Laird et al., 2013). However, reported examples of African Muslim refugee youths' experiences extend beyond reinforcing general knowledge and provide more specific information. First, results in this study are consistent with earlier studies (Abu El-Haj, 2007; Khanlou et al., 2008) that identified discrimination against Muslim students as endemic and perpetrated by peers and educators/administrators. Second, findings revealed the disturbing incidence of bullying and harassment (Aroian, 2012; Abu El-Haj, 2007; Khanlou et al., 2008; Laird et al., 2013), including experiences of overt racism against students perceived to be ethnically/culturally and racially different 
from their U.S.-born peers. Third, the study findings indicate that youth do not report hostile encounters to school administrators out of fear of reprisal or suspension. Most notably, enduring experiences of discrimination were not reported because students felt their status as non-U.S. citizens were the reason school administrators failed to address such concerns. These findings highlight the importance of considering racism and discrimination when studying postresettlement experiences of refugee students.

In contrast, study findings suggest that refugee students choose coping strategies based on calculated judgements, and that "doing nothing" might be indicative of their self-control and maturity. Farwell (2001) and others however contend that doing nothing and self-control, including patience and avoidance (Matheson, Jorden, \& Anisman, 2008), are adaptive coping strategies developed by youth who have been exposed to traumatic events. In fact, for some refugee youth these traits were found to be essential for survival during their exile (Farwell, 2001; Matheson et al., 2008). Lazarus and Folkman (1984) defines these as emotion-focused coping strategies, as they "do not change the meaning of the event [or experience] directly" (pp. 150-151) and may occur when the refugee youth has decided there is nothing that can be done about the situation directly.

Prior research has documented the tendency to homogenize refugees into a single pathologized identity (Muecke, 1992). Very rarely is there a desire to reach into the newcomers' world to understand their unique experiences (Watters, 2001), and to assess their needs in their new environment. Notwithstanding the mental health symptoms resulting from cumulative trauma and experiences of discrimination, respondents described a variety of coping mechanisms that were instrumental to adapting to a sometimes-hostile school environment. In fact, positive maternal parenting including "structure" and "strict rules" played a significant role in the lives of these African refugee youth. Cultural family patterns influenced their decisions to engage in pro-social behavior, persevere, and attain their educational goals. Findings also indicate that negative encounters are counterbalanced by refugee students' optimism, motivation for academic success, religiosity, and ethnic/cultural solidarity and contributed to their resilience. These strategies may be viewed as potential factors for resiliency in these African youth with refugee status, and merits further attention in future research.

Western cultures make assumptions about refugee youth based largely on the media portrayals, "often revealed to provoke pity in the spectator" (Freedman, 2007, p.1). On the contrary, participants expressed that living in the refugee camps "was basically about survival"- constantly strategizing about one's "safety," and most importantly worrying about the "next meal." In other words, refugee youth learned decision-making and "survival skills" that most of their U.S.-born peers probably have not experienced. Thus, students emphasized 
that sharing their story is necessary so that the dominant culture recognizes the "strengths" they bring to their host community, instead of the perception that they are "at risk" youth and/or youth with only deficits. Youth in this sample have an important story in addition to learning English. This finding mirrors Turner's (1992) work reminding us that "telling the trauma story serves not just to assist in the processing of emotions with which it is associated; it is also the first step in the construction of a new story, a new understanding of the past and a new hope for the future" (as cited in Watters, 2001, p. 171).

An important contribution of this study is its qualitative methodology, which is arguably more suited to in-depth understanding of the refugee youths' lived reality and the role of meaning-making in respondent accounts of their experiences. Despite these advances, however, there are certain limitations that need to be acknowledged. The use of retrospective narratives as part of the qualitative methodology is always subject to the potential reconstruction of events resulting from recall imperfections and retrospective interpretation. This process may impact upon reliability of the findings. Furthermore, the small sample size and the heterogeneous nature of the sample in terms of time spent during the period of transition in the U.S. needs to be considered in terms of the generalization of the findings to all African refugee youth as a whole, both in America and internationally.

This qualitative study has several implications for practice. These findings, supported by the data, provide an important contribution to the literature particularly in the broader U.S. context. Of the 56,384 admitted refugees to the United States in 2011,38\% were dependent children, ages 19 and younger (Martin \& Yankay, 2012). Education is therefore essential in considering the meaningful integration of African refugee youth into their new societies. In order to facilitate the academic, emotional, and cultural needs of students from refugee backgrounds, educators must be provided with the necessary training, support, and resources so that they may, in turn, help African Muslim students maximize their educational experience. As schools become increasingly diverse, educators need to also look beyond curriculum objectives and the depersonalized structures (McBrien, 2005; Shah, 2006). They should, instead, begin by showing concern for our individual learners and their unique experiences and family (e.g., economical, political, and social) context.

Refugee students have been through varying degrees of trauma. It is therefore imperative that social workers in schools become aware of the high level of pre-migration trauma, including related mental health symptoms that might affect refugee students' emotional, intellectual, physical, and social wellbeing. Social workers in schools also play an important role in: (a) early detection for refugee youth who are mentally distressed and whose symptoms appear to be persistent; (b) gaining the requisite knowledge and skills to provide culturally responsive mental health services that address the diverse concerns students 
from refugee backgrounds; (c) understanding refugee youths' help-seeking behaviors and coping strategies; (d) build on youths' resiliencies while not ignoring the pain; and (e) foster problem solving strategies to promote social relationships in school and develop interventions that concur with African refugee youth who are at the margins of U.S. society.

Future studies utilizing larger samples may be able to more closely examine specific groups and assess key patterns in settings and perpetrators of discrimination toward African Muslim youth. However, it is hoped that the findings in this study will provide a basis for further investigations of newcomers and, particularly, the factors that contribute to African refugee youths' positive educational outcomes, resilience and psychological wellbeing in their schooling environment. Given the influx of refugee youth in U.S. public schools, a stronger evidence base for care and interventions is needed. Overall, this study's findings can be useful in informing the development of culturally responsive practices and interventions.

\section{References}

Abu-Ras, W., \& Abu-Bader, S. H. (2008). The impact of the September 11, 2001 attacks on the wellbeing of Arab Americans in New York City. Journal of Muslim Mental Health, 3, 217-239.

Abu El-Haj, T. R. (2007). "I was born here, but my home, it's not here": Educating for democratic citizenship in an era of transnational migration and global conflict. Harvard Educational Review, 77, 285-316.

Andary, L., Stolk, Y., \& Klimidis, S. (2003). Assessing mental health across cultures. Brisbane: Australian Academic Press.

Anjum, T. M., Nordqvist, C., \& Timpka, T. (2011). The hopes of West African refugees during resettlement in northern Sweden: A 6-year prospective qualitative study of pathways and agency thoughts. Conflict and health, 6, doi: 10.1186/1752-1505-6-1.

Annie E. Casey Foundation (2007). Kids count data book collection. Retrieved July 9, 2014, from http://www.aecf.org/m/resourcedoc/AECF-KidsCountDataBook-2007.pdf

Aroian, K. J. (2012). Discrimination against Muslim American adolescents. Journal of School Nursing, 28, 206-13.

Boeije, H. R. (2002). A purposeful approach to the constant comparative method in the analysis of qualitative interviews. Quality \& Quantity, 36, 391-409.

Camarota, S.A. (2012). Immigrants in the United States, 2010: A profile of America's foreign-born population. Retrieved August 3, 2014, from http://www.cis.org/sites/ cis.org/files/articles/2012/immigrants-in-the-united-states-2012.pdf

Casimiro, S., Hancock, P., \& Northcote, J. (2007). Isolation and insecurity: Resettlement issues among Muslim refugee women in Perth, Western Australia. Australian Journal of Social Issues, 42, 55-69.

Child Trends (2013). High school dropout rates. Retrieved August 9, 2014, from http:// www.childtrends.org/?indicators=high-school-dropout-rates

Creswell, J. W. (2007). Qualitative inquiry \& research design: Choosing among five approaches. Thousand Oaks, CA: Sage Publications. 
Darboe, K. (2003). New immigrants in Minnesota: The Somali immigration and assimilation. Journal of Developing Societies 19, 458-472.

Daud, A., af Klinteberg, B., \& Rydelius, P.-A. (2008). Resilience and vulnerability among refugee children of traumatized and non-traumatized parents. Child and Adolescent Psychiatry and Mental Health, 2(7), 1-11.

Deacon, Z., \& Sullivan, C. (2009). Responding to the complex and gendered needs of refugee women. Affilia, 24, 272-284.

De Anstiss, H., \& Ziaian,T. (2010). Mental health help-seeking and refugee adolescents: qualitative findings from a mixed-methods investigation. Australian Psychologist, 45, 29-37.

Ellis, B. H., MacDonald, H. Z., Lincoln, A. K., \& Cabral, H. J. (2008). Mental health of Somali adolescent refugees: The role of trauma, stress, and perceived discrimination. Journal of Consulting and Clinical Psychology, 76, 184-193.

Farwell, N. (2001). "Onward through strength": Coping and psychological support among refugee youth returning to Eritrea from Sudan. Journal of Refugee Studies, 14, 43-69. doi:10.1093/jrs/14.1.43

Fazel, M., \& Stein, A. (2002). Mental health of refugee children. Archives of Disease in Childhood, 87, 366-370.

Fazel, M., Reed, R. V., Panter-Brick, C., \& Stein, A. (2012). Mental health of displaced and refugee children resettled in high-income countries: Risk and protective factors. Lancet, 379, 266-282.

Fong, R. (2007). Immigrant and refugee youth: Migration journeys and cultural values. Prevention Researcher, 14(4), 3-5.

Freedman, J. (2007). Gendering the international asylum and refugee debate. Basingstoke, UK: Palgrave Macmillan.

Hauck, F. R., Corr, K. E., Lewis, S. H., \& Oliver, M. N. (2012). Health and health care of African refugees: An underrecognized minority. Journal of the National Medical Association, 104(1-2), 61-71.

Hek, R. (2005). The role of education in the settlement of young refugees in the UK: The experiences of young refugees. Practice, 17, 157-171.

Hinton, D. E., Chhean, D., Pich, V., Safren, S. A., Hofmann, S. G., \& Pollack, M. H. (2005). A randomized controlled trial of cognitive-behavior therapy for Cambodian refugees with treatment-resistant PTSD and panic attacks: A cross-over design. Journal of Traumatic Stress, 18, 617-629. doi:10.1002/jts.20070

Hodes, M. (2002). Three key issues for young refugees' mental health. Transcultural Psychiatry, 39, 196-213.

Kanu, Y. (2008). Educational needs and barriers for African refugee students in Manitoba. Canadian Journal of Education, 31, 915-940.

Khanlou, N., Koh, J. G., \& Mill, C. (2008). Cultural identity and experiences of prejudice and discrimination of Afghan and Iranian immigrant youth. International Journal of Mental Health and Addiction, 6, 494-513.

Kirova, A. (2001). Loneliness in immigrant children: Implications for classroom practice. Childhood Education, 77, 260-267.

Kugler, E. G. (2009, June). Partnering with parents and families to support immigrant and refugee children at School. (Issue brief No. 2). Washington, DC: Robert Wood Johnson Foundation.

Laird, L. D., Abu-Ras, W., \& Senzai, F. (2013). Cultural citizenship and belonging: Muslim international medical graduates in the USA. Journal of Muslim Minority Affairs, 33, 356-370. 
Law, B., \& Eckes, M. (2000). The more-than-just-surviving handbook: ESL for every classroom teacher ( $2^{\text {nd }}$ ed.). Winnipeg: Portage \& Main Press.

Lazarus, R., \& Folkman, S. (1984). Stress, appraisal and coping. New York: Springer.

MacNevin, J. (2012). Learning the way: Teaching and learning with and for youth from refugee backgrounds on Prince Edward Island. Canadian Journal of Education, 35(3), 48-63.

Martin, D. C., \& Yankay, J. E. (2012). Refugees and asylees: 2011. Retrieved March 6, 2013, from http://www.dhs.gov/xlibrary/assets/statistics/publications/ois_rfa_ fr_2011.pdf

Matheson, K., Jorden, S., \& Anisman, H. (2008). Relations between trauma experiences and psychological, physical and neuroendocrine functioning among Somali refugees: Mediating role coping with acculturation stressors. Journal of Immigrant and Minority Health, 10, 291-304. doi: 10.1007/s10903-001-9086-2.

Matthews, J. (2008). Schooling and settlement: Refugee education in Australia. International Studies in Sociology of Education, 18, 31-45.

McBrien, J. L. (2005). Educational needs and barriers for refugee students in the United States: A review of the literature. Review of Educational Research, 75(3), 329-364.

Miller, K. E., \& Rasco, L. M. (2004). The mental health of refugees: Ecological approaches to healing and adaptation. Mahwah, NJ: Erlbaum.

Muecke, M. A. (1992). New paradigms for refugee health problems. Social Science \& Medicine 35, 515-523.

Muhr, T. (2004). ATLAS.ti 7.0. Berlin: Scientific Software Development.

Onsando, G., \& Billett, S. (2009). African students from refugee backgrounds in Australian TAFE institutes: A case for transformative learning goals and processes. International Journal of Training Research, 7(2), 80-94.

Ovitt, N., Larrison, C. R., \& Nackerud, L. (2003). Refugees' responses to mental health screening: A resettlement initiative. International Social Work, 46, 235-250.

Pacione, L., Measham, T., \& Rousseau, C. (2013). Refugee children: Mental health and effective interventions. Current psychiatry reports, 15, 341-349.

Rossiter, M. J., \& Rossiter, K. R. (2009). Diamonds in the rough: Bridging gaps in supports for at-risk immigrant and refugee youth. Journal of International Migration and Integration, 10 (4), 409-429.

Ruf, M., Neuner, F., Elbert, T., Schauer, M., Kurreck, S., \& Odenwald, M. (2010). Can asylum-seekers with posttraumatic stress disorder be successfully treated? A randomized controlled pilot study. Cognitive Behaviour Therapy, 39(2), 81-91. doi:10.1080/16506070903121042

Saldaña, J. (2013). The Coding Manual for Qualitative Researchers. Los Angeles: Sage.

Segal, U. A., \& Mayadas, N. S. (2005). Assessment of issues facing immigrant and refugee families. Child Welfare, 84, 563-83.

Slobodin, O., \& de Jong, J. T. (2015). Mental health interventions for traumatized asylum seekers and refugees: What do we know about their efficacy? International Journal of Social Psychiatry, 61, 17-26. doi:10.1177/0020764014535752

Tadesse, S., Hoot, J., \& Watson-Thompson, O. (2009). Exploring the special needs of African refugee children in U.S. schools. Childhood Education, 85, 352-356.

Shah, S. (2006). Leading multiethnic schools: A new understanding of Muslim youth identity. Educational Management Administration \& Leadership, 34(2), 215-237.

Shakya, Y. B., Guruge, S., Hynie, M., Akbari, A., Malik, M., Htoo, S. et al. (2010). Aspirations for higher education among newcomer refugee youth in Toronto: Expectations, challenges, and strategies. Refugee, 27(2), 65-78. 
Suárez-Orozco, C., Pimentel, A., \& Martin, M. (2009). The significance of relationships: Academic engagement and achievement among newcomer immigrant youth. Teachers College Record, 111, 712-749.

Suárez-Orozco, C., \& Suárez-Orozco, M. M. (2001). Children of immigration. Cambridge, MA: Harvard University Press.

Taylor, S., \& Sidhu, R. K. (2012). Supporting refugee students in schools: What constitutes inclusive education? International Journal of Inclusive Education, 16, 39-56.

Tindongan, C. W. (2011). Negotiating Muslim youth identity in a post-9/11 world. The High School Journal, 95, 72-87.

Tyrer, R. A., \& Fazel, M. (2014). School and community-based interventions for refugee and asylum seeking children: A systematic review. PloS One, 9(2), e89359. doi:10.1371/journal.pone.0089359

UN High Commissioner for Refugees (UNHCR). The state of the world's refugees: In search of solidarity, 2012. Retrieved March 13, 2014, from http://www.unhcr. org/4fc5ceca9.html

Watters, C. (2001). Emerging paradigms in the mental health care of refugees. Social Science \& Medicine, 52, 1709-1718.

Zine, J. (2001). Muslim youth in Canadian schools: Education and the politics of religious identity. Anthropology \& Education Quarterly, 32, 399-423. 